\title{
Article \\ Exploiting Thrips Aggregation Pheromones to Develop a Lure-and-Kill Strategy for the Management of the Bean Flower Thrips
}

\author{
David K. Mfuti ${ }^{1}$, Amanuel Tamiru ${ }^{1, *}{ }^{\mathbb{D}}$, William D. J. Kirk ${ }^{2}$, Adeyemi O. Akinyemi ${ }^{1,3}{ }^{3}$, Heather Campbell ${ }^{4}$, \\ Matthew $\mathrm{O}^{\prime}$ Brien $^{2}$, Falko P. Drijfhout ${ }^{2}$, Tom W. Pope ${ }^{4}$, Saliou Niassy ${ }^{1}$ (I) and Sevgan Subramanian ${ }^{1}$ (I) \\ 1 International Centre of Insect Physiology and Ecology, Nairobi P.O. Box 30772-00100, Kenya; \\ dkupesa@icipe.org (D.K.M.); yemiakinyemi2011@gmail.com (A.O.A.); sniassy@icipe.org (S.N.); \\ ssubramania@icipe.org (S.S.) \\ 2 Faculty of Natural Sciences, Keele University, Staffordshire ST5 5BG, UK; w.d.j.kirk@keele.ac.uk (W.D.J.K.); \\ m.obrien@keele.ac.uk (M.O.); f.drijfhout@keele.ac.uk (F.P.D.) \\ 3 Department of Agronomy, Osun State University, Osogbo PMB 4494, Nigeria \\ 4 Centre for Integrated Pest Management, Agriculture and Environment Department, Harper Adams \\ University, Newport, Shropshire TF10 8NB, UK; hcampbell@harper-adams.ac.uk (H.C.); \\ tpope@harper-adams.ac.uk (T.W.P.) \\ * Correspondence: atamiru@icipe.org; Tel.: +254-20-8632-2041
}

Citation: Mfuti, D.K.; Tamiru, A.; Kirk, W.D.J.; Akinyemi, A.O.; Campbell, H.; O’Brien, M.; Drijfhout, F.P.; Pope, T.W.; Niassy, S.; Subramanian, S. Exploiting Thrips Aggregation Pheromones to Develop a Lure-and-Kill Strategy for the Management of the Bean Flower Thrips. Agronomy 2021, 11, 1269. https://doi.org/10.3390/ agronomy 11071269

Academic Editors: Patrick Pageat and Andrea Liliana Clavijo McCormick

Received: 30 April 2021

Accepted: 16 June 2021

Published: 22 June 2021

Publisher's Note: MDPI stays neutral with regard to jurisdictional claims in published maps and institutional affiliations.

Copyright: () 2021 by the authors. Licensee MDPI, Basel, Switzerland. This article is an open access article distributed under the terms and conditions of the Creative Commons Attribution (CC BY) license (https:// creativecommons.org/licenses/by/ $4.0 /)$.
Abstract: The potential of semiochemicals to lure insect pests to a trap where they can be killed with biopesticides has been demonstrated as an eco-friendly pest management alternative. In this study, we tested two recently characterized male-produced aggregation pheromones of the bean flower thrips Megalurothrips sjostedti (Trybom), namely (R)-lavandulyl 3-methylbutanoate (major) and $(R)$-lavandulol (minor), for their field efficacy. Moreover, compatibility of these pheromones and two other thrips attractants, Lurem-TR and neryl (S)-2-methylbutanoate, with the entomopathogenic fungus (EPF) Metarhizium anisopliae ICIPE 69 has been determined. Our study revealed that the M. sjostedti aggregation pheromones have dose-dependent antifungal effects on the EPF viability, but showed no fungistatic effect at a field-realistic dose for attraction of thrips. (R)-lavandulyl 3methylbutanoate had similar antifungal effects as neryl (S)-2-methylbutanoate 8 days after exposure; whereas, Lurem-TR had a stronger antifungal effect than other thrips attractants. In the semi-field experiments, all autoinoculation devices maintained at least $86 \%$ viability of M. anisopliae conidia after 12 days of exposure. Field trials demonstrated for the first time that $(R)$-lavandulyl 3-methylbutanoate increases trap catches. Our findings pave a way for designing a lure-and-kill thrips management strategy to control bean flower thrips using autoinoculation devices or spot spray application.

Keywords: Thripidae; Metarhizium anisopliae; Megalurothrips sjostedti; compatibility; lavandulyl 3-methylbutanoate; lavandulol; methyl isonicotinate

\section{Introduction}

Grain legumes are grown as staple crops by millions of smallholder farmers across sub-Saharan Africa and are important sources of protein to the urban and rural poor who cannot afford meat, fish, or milk products [1,2]. Despite their wide range of uses, production and productivity of the crop is hampered by various biotic and abiotic factors. The bean flower thrips, Megalurothrips sjostedti Trybom (Thysanoptera: Thripidae) is among the key pests of grain legumes in the region [3-5]. The pest attacks a wide range of crops, mainly in the legume family (Fabaceae), especially cowpea, Vigna unguiculata (L.) Walp. and French bean, Phaseolus vulgaris (L.) [6,7]. Megalurothrips sjostedti causes abscission of flowers resulting in significant yield losses ranging between 21 and 83\% [8]. Some farmers resort to using synthetic chemical insecticides to control $M$. sjostedt $i 3,9]$ which is not an environmentally benign pest control option; while the majority of the smallholder farmers 
in the region cannot afford and/or get easy access to chemical pesticides and leave the crop unmanaged [10]. The development of ecologically friendly bean flower thrips management alternatives will not only prevent undesirable consequences of chemical pesticides but also leads to improved production of healthier yields and better safety to growers and consumers. For example, a potential of entomopathogenic fungus-based biopesticide such as Metarhizium anisopliae (Metschnikoff) Sorokin strain ICIPE 69 for sustainable pest management has been demonstrated in East Africa [3,11-13].

Recently, male-produced aggregation pheromones of the bean flower thrips have been characterized as consisting of two distinct compounds, namely $(R)$-lavandulyl 3methylbutanoate (major component) and (R)-lavandulol (minor component) [14]. Laboratory behavioral studies using synthetic compounds showed that both male and female $M$. sjostedti were attracted to $(R)$-lavandulyl 3-methylbutanoate in an olfactometer, while (R)-lavandulol attracted males only [14]. Pheromone-mediated aggregation behavior could allow male-male or male-female conidial transmission during aggregation and mating as it has previously been observed in other insect species $[15,16]$. Conidial transmission potential between thrips during aggregation could create an opportunity to develop improved biopesticides application techniques by exploiting semiochemical attractants for "lure-andkill" strategies using autoinoculation devices or spot spray applications. Such strategies have been shown to reduce the quantity of inoculum required and the cost of application while ensuring fungal persistence in the field $[3,12,17]$. However, the success of such a strategy depends on the compatibility of the semiochemical with the entomopathogenic fungus. For example, Niassy et al. [18] observed inhibitory effects of thrips attractant Lurem-TR (methyl isonicotinate) on M. anisopliae conidia within an autoinoculation device in a screenhouse experiment. To overcome the challenge, Mfuti et al. [19] demonstrated, under field conditions, that an optimal separation of $10 \mathrm{~cm}$ between Lurem-TR placed outside the autoinoculation device and the conidial source within the device resulted in increased $M$. sjostedti attraction and enhanced compatibility between the fungus and Lurem-TR. Among some other thrips attractants, methyl anthranilate has been found to be compatible with $M$. anisopliae and was equally attractive to M. sjostedti as Lurem-TR [20].

Information on compatibility of the aggregation pheromones of thrips, including the M. sjostedti pheromone with entomopathogenic fungi is lacking. In the current study, we investigated the compatibility of both major and minor M. sjostedti aggregation pheromone components with the entomopathogenic fungus, M. anisopliae isolate ICIPE 69. Further, the compatibility of $M$. sjostedti pheromone compounds was compared in the laboratory with two other commercial thrips attractants: Lurem-TR (methyl isonicotinate) and neryl (S)-2-methylbutanoate, which is the major component of the aggregation pheromone of the western flower thrips, Frankliniella occidentalis (Pergande). Prior to assessing the compatibility in the semi-field, we conducted a field experiment to test whether the major component of the $M$. sjostedti aggregation pheromone increased trap catches and at the same time established the effective dose. This research is an important step in developing an effective "lure-and-kill" thrips management strategy. The development of semiochemical and biopesticide-based thrips management strategies will provide ecologically sustainable M. sjostedti control alternatives and help reduce reliance on harmful chemical pesticides.

\section{Materials and Methods}

\subsection{Study Site}

Laboratory experiments were conducted at the International Centre of Insect Physiology and Ecology (icipe), Duduville Kasarani, Kenya $\left(1.221^{\circ}\right.$ S, 36.896 ${ }^{\circ}$ E; 1616 m above sea level). The semi-field experiment was conducted at icipe Duduville campus while the field experiment for screening effective dose of $M$. sjostedti aggregation pheromone was conducted at the icipe Thomas Odhiambo Campus (ITOC), Mbita, western Kenya $\left(0^{\circ} 26^{\prime} 06.19^{\prime \prime} \mathrm{S}, 34^{\circ} 12^{\prime} 53.13^{\prime \prime} \mathrm{E} ; 1137 \mathrm{~m}\right.$ above sea level $)$. All experiments were conducted from October 2018 to April 2020. 


\subsection{Pheromones and Attractants Used}

Authentic standards of pheromone components, $(R)$-lavandulyl 3-methylbutanoate (major component) and $(R)$-lavandulol (minor component) were synthesized at Keele University, UK. The $(R)$-lavandulyl 3-methylbutanoate ester was synthesized by reaction of (R)-lavandulol with 3-methylbutanoyl chloride in dichloromethane at $0{ }^{\circ} \mathrm{C}$, in the presence of triethylamine and catalytic DMAP. The $(R)$-lavandulol was synthesized according to the procedures published by Pepper et al. [21]. The synthesis used Evans alkylation of the corresponding 3,3-dimethylacryloyl benzyloxazolidinone with prenyl bromide, followed by hydride reduction of the purified oxazolidinone to the primary alcohol. Both compounds had a purity of at least $99 \%$ and an enantiomeric excess (ee) of at least $99 \%$.

The major compound of the F. occidentalis aggregation pheromone, neryl (S)-2-methylbutanoate, was obtained from Russell IPM, Deeside Industrial Park, Deeside, Flintshire, UK (www.russellipm.com, accessed on 17 June 2021). The product is commercialized under the name of "Frankliniella occidentalis lure" coded PH-339-1RR. Only one quantity of the commercialized pheromone product was available and hence only one release rate and concentration was tested in this study. The dose of neryl (S)-2-methylbutanoate in commercial lures is $30 \mu \mathrm{g}[22,23]$.

A commercially produced thrips attractant Lurem-TR, with the active ingredient methyl-isonicotinate (MI), was included in this study as a positive check because of its antifungal effect $[20,24]$. Lurem-TR was previously reported to be effective in monitoring thrips populations [25-27]. Lurem-TR was obtained from Pherobank (Wageningen, The Netherlands). A dose of $30 \mu \mathrm{g}$ was used for the bioassay obtained by squeezing out the product and weighing it on a sensitive balance.

Sterile distilled water $(10 \mathrm{~mL}$ ) containing 0.05\% Triton X-100 (Loba Chemie Pvt, Mumbai, India) was used as a negative control.

\subsection{Blue Sticky Traps}

Commercially available dry blue sticky traps $(10 \times 25 \mathrm{~cm})$ were obtained from Real IPM Ltd., Thika, Kenya.

\subsection{Rubber Septa Dispensers}

Rubber septa dispensers were obtained from International Pheromone Systems Ltd., Wirral, UK. Before use, the rubber septa ( $20 \mathrm{~mm}$ long with $9 \mathrm{~mm} \times 1.5 \mathrm{~mm}$ deep cup) were cleaned with hexane using Soxhlet extraction to eliminate any volatile contaminants that could affect the results [28].

\subsection{Fungal Culture}

Metarhizium anisopliae isolate ICIPE 69 was obtained from the repository of entomopathogens maintained at icipe's Arthropod Pathology Unit. It is currently commercialized as Mazao-Campaign ${ }^{\circledR}$ by Real IPM Ltd., Thika, Kenya, for the control of thrips, papaw mealybug and fruit flies. The fungus was cultured on Sabouraud Dextrose Agar (SDA) in $9 \mathrm{~cm}$ diameter Petri dishes and put in an incubator at $25 \pm 2{ }^{\circ} \mathrm{C}$, in complete darkness for three weeks. Conidia were harvested from the three-weeks-old culture by scraping the surface using a spatula [29]. Conidia were suspended in $10 \mathrm{~mL}$ sterile distilled water containing $0.05 \%$ Triton X-100 (Loba Chemie Pvt, Mumbai, India) in universal bottles containing glass beads. Conidial suspensions were vortexed for $5 \mathrm{~min}$ to produce a homogeneous suspension. Spore concentrations were determined using a hemocytometer. The percentage of germination was determined by counting 100 spores, categorized as germinated and non-germinated, under each coverslip on each Petri plate under a light microscope ( $400 \times$ magnification). A conidium was considered to have germinated if the germ tube was at least twice the size of the spore. The percentage of viable spores was confirmed to be over $90 \%$ before a suspension was used in any experiment. 
2.6. Effects of Thrips Aggregation Pheromones and Non-Pheromone Attractant on M. anisopliae Conidial Viability

Conidial suspension was prepared as described above and titrated to a spore concentration of $1 \times 10^{7}$ conidia $\mathrm{mL}^{-1}$. The spores were retained on a nitrocellulose filter membrane (diameter $47 \mathrm{~mm}$, pore size $0.45 \mu \mathrm{m}$, Sigma-Aldrich, Darmstadt, Germany) by pouring $10 \mathrm{~mL}$ suspension through a filter holder unit microfiltration system under aspirator vacuum $[20,30]$. The nitrocellulose filter membranes were dried for $30 \mathrm{~min}$ in a laminar flow cabinet and transferred to glass desiccators (2.5 liters) for exposure to $(R)$-lavandulyl 3-methylbutanoate, $(R)$-lavandulol, neryl (S)-2-methylbutanoate, or Lurem-TR. To assess the effects of $M$. sjostedt $i$ aggregation pheromone doses on fungal viability, three doses, i.e., 1,10 , and $100 \mu \mathrm{L}$ of the authentic product of each pheromone compound, were dispensed onto a rubber septum. For comparing the antifungal effects of $M$. sjostedti aggregation pheromone compounds with the non-pheromone attractant and F. occidentalis aggregation pheromone, a standard dose of $30 \mu \mathrm{g}$ (equivalent to $0.03 \mu \mathrm{L}$ ) was used. A 30- $\mu \mathrm{g}$ dose has been standardized for applications of thrips pheromones under field conditions [22,23]. A dispenser containing the standard dose of $30 \mu \mathrm{g}$ was used for the major compound of $F$. occidentalis aggregation pheromone. Separate desiccators were used for each tested compound. Five nitrocellulose membranes were placed together at the same time on a perforated shelf inside each desiccator at $15 \mathrm{~cm}$ distance from the septum. Fungus-treated membranes were sampled at different time intervals of 1, 2, 3, 6, and 8 days to record the effect of each test compound on spore viability over time. Spore germination was assessed after 18 and $24 \mathrm{~h}$ of incubation. Fungal germination was assessed to determine if all tested semiochemicals affect the viability of conidia as has previously been evidenced for Lurem-TR [18,20]. All treatments were randomized and replicated four times.

To determine conidial germination, nitrocellulose filter membranes containing conidia spores were removed from the desiccators and transferred into $10 \mathrm{~mL}$ sterile distilled water containing $0.05 \%$ Triton X-100 and vortexed for 3 min to dislodge conidia. A suspension $(0.1 \mathrm{~mL})$ titrated to $3 \times 10^{6}$ conidia $\mathrm{mL}^{-1}$ was spread-plated on Sabouraud Dextrose Agar (SDA) plates. Plates were placed in an incubator as described earlier at $26 \pm 2{ }^{\circ} \mathrm{C}, 65 \pm 5 \%$ $\mathrm{RH}, \mathrm{L} 12$ : D12 photoperiod and conidial germination examined after 18 and $24 \mathrm{~h}$. Samples that could not be processed the same day were fixed by pouring a drop of lactophenol cotton blue onto the plate to stop further growth. Percentage germination was determined by counting approx. 100 spores, categorized as germinated or non-germinated, under each coverslip from each Petri plate under a microscope (Leica DMLB) at $400 \times$ magnification. A conidium was considered to have germinated if the germ tube length was at least twice the diameter of the spore [31].

2.7. Effect of Thrips Aggregation Pheromone and Non-Pheromone Attractants on M. anisopliae Conidial Germ Tube Growth

After the assessment of conidial germination, the growth of germ tubes was further measured using a Leica microscope camera (200× magnification) after 18 and $24 \mathrm{~h}$. Average germ tube growths were obtained from five germinated spores selected randomly in each coverslip [20]. The experiment was replicated three times.

\subsection{Attraction of M. sjostedti to the Major Compound of Its Aggregation Pheromone}

The field trapping experiments for different doses of major compound of $M$. sjostedt $i$ aggregation pheromone were conducted at Mbita from September 2018 to February 2019. The aim here is to test our promising initial lab-based findings [14] under realistic field conditions and screen the field-effective dose of the major compound of $M$. sjostedti aggregation pheromone for thrips management. The period of the experiment corresponded to the short rainy season (September-December) and the dry season (January-March). Data collection on $M$. sjostedti catches was conducted for one-day period depending on thrips population, with a minimum of 20 thrips in the control trap used to determine the length of the trapping period. The experiment was set during flowering and podding stages. The 
number of male and female $M$. sjostedt $i$ was recorded by counting separately their numbers on the blue sticky traps. Power light and magnifying glass were used for counting. After completing the counting, blue sticky cards were wrapped gently with cling film and kept in a fridge for further investigations.

\subsection{Effect of Major Compound of M. sjostedti Aggregation Pheromone on M. anisopliae Persistence in an Autoinoculation Device}

A semi-field experiment using an autoinoculation device was conducted at icipe Duduville to assess the effect of $30 \mu \mathrm{g}$ dose of the major compound of the M. sjostedti aggregation pheromone on $M$. anisopliae persistence. The autoinoculation device used in this experiment was blue as described by Mfuti et al. [24]. The blue trap $(16 \mathrm{~cm}$ diameter $\times 16 \mathrm{~cm}$ high) was perforated with six entry/exit holes $(5 \mathrm{~cm}$ diameter $)$ right in the middle of the bottle, at alternate positions. A velvet cloth $(8 \times 8.5 \mathrm{~cm})$ and a white netting $(3.5 \times 11 \mathrm{~cm})$ were wrapped around a smaller inner cylindrical bottle $(6.5 \mathrm{~cm}$ diameter $\times 6 \mathrm{~cm}$ high) that was then hung in the trap. Approximately 2-3 g of dry conidia was spread evenly on the velvet cloth of the autoinoculation device.

A septum with $30 \mu \mathrm{g}$ of (R)-lavandulyl 3-methylbutanoate (major compound of $M$. sjostedti aggregation pheromone) was placed in two set-ups in the autoinoculation device (1) inside the inner cylindrical bottle in direct exposure with conidial spores (without spatial separation), (2) inside a small container $(6.5 \mathrm{~cm}$ diameter $\times 12 \mathrm{~cm}$ high $)$ fixed just above the device spatially separated from the spores [24]. The small container was perforated with six holes ( $0.7 \mathrm{~cm}$ diameter) to allow volatiles to be released. A septum with solvent (hexane) only in an inoculation device was used as a control. The persistence of $M$. anisopliae conidia was evaluated for a period of 12 days after the onset of the experiment in the field. At 3-day intervals, samples of conidia were collected from the autoinoculation devices with a moist cotton bud. The end of the cotton bud was cut, suspended in $10 \mathrm{~mL}$ of $0.05 \%$ $(w / v)$ Triton X-100 and vortexed for 1 min to dislodge conidia. A conidial suspension sample $(100 \mu \mathrm{L})$ was spread-plated on SDA plates and incubated for $16 \mathrm{~h}$ at $25 \pm 2{ }^{\circ} \mathrm{C}$ and L12: D12 photoperiod. Germination of conidia was determined as described above. The autoinoculation devices were separated by $10 \mathrm{~m}$ and the experiment was replicated three times.

\subsection{Statistical Analysis}

Data on $M$. anisopliae conidial germ tube growth and conidial germination were transformed and analyzed using a linear mixed model with a random intercept. Leastsquares means were estimated using the emmeans package [32]. The means were then separated and adjusted using Tukey's honestly significant difference (HSD) test at 5\% significance level [32]. Repeated measures logistic regression model implemented using generalized estimating equations was used to estimate the time taken to reach $50 \%$ viability across different treatments for viability data collected over five time points. Data on $M$. sjosted $i$ catches at different doses of the major compound were analyzed using a generalized linear model with a negative binomial distribution due to over dispersion of the catch data. The means were compared with the Tukey HSD test at 5\% significance level. For the semi-field experiments on the effect of $30 \mu \mathrm{g}$ of dose of major compound on fungal persistence, repeated-measures ANOVA was used. All data analyses were performed using $\mathrm{R}$ version 3.5.3 [33].

\section{Results}

3.1. Effect of M. sjostedti Aggregation Pheromone Components on Conidial Viability and Germ Tube Growth

Both $M$. sjostedti aggregation pheromone components significantly reduced $M$. anisopliae conidial viability and germ tube growth at higher doses. The lowest test dose $(1 \mu \mathrm{L})$ of the M. sjostedti aggregation pheromone components did not have an antifungal effect (germination: $\mathrm{F}_{2,15}=3.4 ; p=0.08$, growth: $\mathrm{F}_{2,9}=0.3 ; p=0.74$ ), whereas $10 \mu \mathrm{L}$ (germination: $\mathrm{F}_{2,15}=42.1 ; p<0.001$, growth: $\mathrm{F}_{2,9}=9.9 ; p<0.001$ ) and $100 \mu \mathrm{L}$ (germination: $\mathrm{F}_{2,15}=8.9$; 
$p<0.001$, growth: $\left.\mathrm{F}_{2,9}=6.5 ; p<0.001\right)$ doses significantly reduced conidial viability and germ tube growth of M. anisopliae (Table 1).

Table 1. Effects of different doses of M. sjostedti aggregation pheromone components on M. anisopliae conidial viability and germ tube growth.

\begin{tabular}{|c|c|c|c|c|c|c|}
\hline \multirow{3}{*}{ Treatments } & \multicolumn{3}{|c|}{$\%$ Germination $\pm \mathrm{SE}$} & \multicolumn{3}{|c|}{ Growth $(\mu \mathrm{m} / \mathrm{Day}) \pm \mathrm{SE}$} \\
\hline & \multicolumn{3}{|c|}{ Dose } & \multicolumn{3}{|c|}{ Dose } \\
\hline & $1 \mu \mathrm{L}$ & $10 \mu \mathrm{L}$ & $100 \mu \mathrm{L}$ & $1 \mu \mathrm{L}$ & $10 \mu \mathrm{L}$ & $100 \mu \mathrm{L}$ \\
\hline Control & $87.5 \pm 0.9 \mathrm{aA}$ & $88.5 \pm 2.0 \mathrm{aA}$ & $86.2 \pm 2.5 \mathrm{aA}$ & $111.0 \pm 6.0 \mathrm{aA}$ & $95.1 \pm 5.6 \mathrm{aA}$ & $92.6 \pm 6.8 \mathrm{aA}$ \\
\hline Major & $86.7 \pm 1.1 \mathrm{aA}$ & $49.1 \pm 6.5 \mathrm{bB}$ & $38.1 \pm 9.8 \mathrm{bB}$ & $108.0 \pm 9.8 \mathrm{aA}$ & $42.6 \pm 6.2 \mathrm{bB}$ & $22.9 \pm 8.0 \mathrm{cC}$ \\
\hline \multirow[t]{2}{*}{ Minor } & $85.8 \pm 1.2 \mathrm{aA}$ & $47.2 \pm 6.8 \mathrm{bB}$ & $42.0 \pm 10.9 \mathrm{bB}$ & $114.0 \pm 7.0 \mathrm{aA}$ & $36.7 \pm 7.3 \mathrm{bB}$ & $34.7 \pm 15.2 \mathrm{bB}$ \\
\hline & $\begin{array}{c}\mathrm{F}_{2,15}=3.4 \\
p=0.08\end{array}$ & $\begin{array}{c}\mathrm{F}_{2,15}=42.1 \\
p<0.001\end{array}$ & $\begin{array}{c}\mathrm{F}_{2,15}=8.9 \\
p<0.001\end{array}$ & $\begin{array}{c}\mathrm{F}_{2,9}=0.3 \\
p=0.74\end{array}$ & $\begin{array}{l}\mathrm{F}_{2,9}=9.9 \\
p<0.001\end{array}$ & $\begin{array}{l}\mathrm{F}_{2,9}=6.5 \\
p<0.001\end{array}$ \\
\hline
\end{tabular}

Means $( \pm$ SE) followed by the same letter(s) within a column (lowercase) and within a row (uppercase) are not significantly different based on Tukey HSD test at 5\% significance level for each parameter (\% germination/growth).

The logistic regression analysis predicted that the probability of a reduction in viability of $50 \%$ corresponds to the lethal doses of $111.3 \mu \mathrm{L}(96.2-132.7 \mu \mathrm{L})$ and $132 \mu \mathrm{L}$ (112.1-162.7 $\mu \mathrm{L})$ for the major and minor compounds, respectively.

3.2. Effects of Thrips Aggregation Pheromones and Non-Pheromone Attractants on M. anisopliae Conidial Viability and Time Taken to Reach 50\% Viability

There was no significant difference in the viability of $M$. anisopliae isolate ICIPE 69 conidia between 18- and 24-h incubation periods after spore exposure to $(R)$-lavandulyl 3-methylbutanoate, neryl $(S)$-2-methylbutanoate or Lurem-TR $\left(\mathrm{F}_{1,109}=2.3 ; p=0.1\right)$. Hence, the incubation time of $18 \mathrm{~h}$ was used to assess the effect of different thrips attractants on fungal viability. Conidial viability of $M$. anisopliae was significantly reduced after exposure to Lurem-TR as compared to the major $M$. sjostedti and F. occidentalis aggregation pheromones or unexposed control $\left(\mathrm{F}_{3,23}=4.6 ; p<0.001\right)$. A sharp decline in conidial viability of M. anisopliae spores was observed one day after exposure to Lurem-TR (Figure 1). The number of exposure days significantly affected the fungal viability; however, there was no significant difference in conidial viability between the major aggregation pheromones of F. occidentalis $(82 \pm 6 \%), M$. sjostedti $(76 \pm 5 \%)$, and the control (85 $\pm 6 \%$ ) (Figure 1 ). Moreover, the shortest time taken to reach $50 \%$ viability was recorded after M. anisopliae exposure to Lurem-TR (1.1 days) followed by F. occidentalis (7.4 days) and M. sjostedti (9.4 days) aggregation pheromones. There was no interaction between all the treatments and exposure days $\left(\mathrm{F}_{16,59}=1.62 ; p=0.25\right)$.

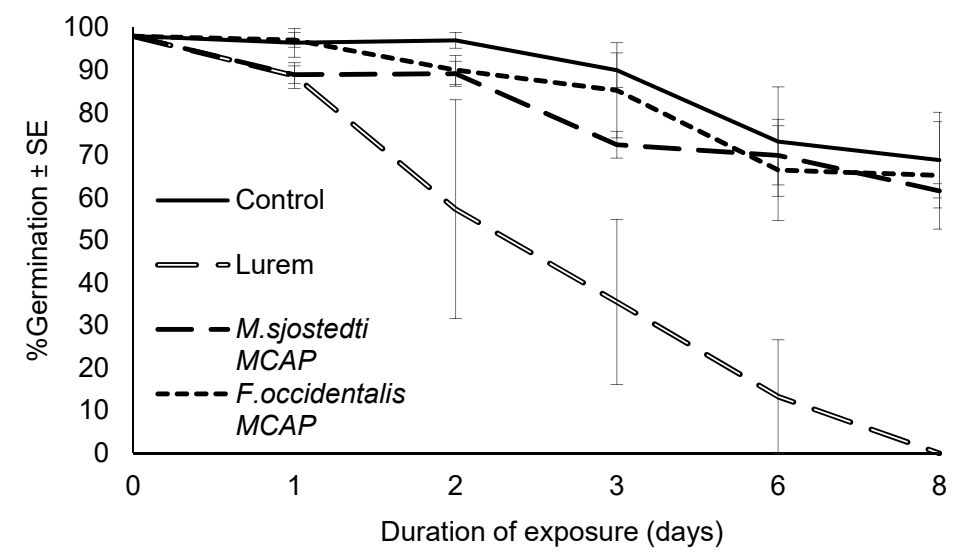

Figure 1. Effect of thrips aggregation pheromones and non-pheromone attractant on M. anisopliae conidial viability after 0 to 8 days of exposure at $30 \mu \mathrm{g}$ dose per attractant. MCAP: major component of aggregation pheromones. 
3.3. Effect of Thrips Aggregation Pheromones and Non-Pheromone Attractant on M. anisopliae Germ Tube Growth

There was a significant difference in M. anisopliae isolate ICIPE 69 germ tube growth, after exposure to the aggregation pheromones and non-pheromone attractant at two incubation periods $\left(\mathrm{F}_{1,239}=70.7 ; p<0.0001\right)$. Germ tube growth of $M$. anisopliae isolate ICIPE 69 was significantly reduced after exposure to $(R)$-lavandulyl 3-methylbutanoate, neryl $(S)$ 2-methylbutanoate, and Lurem-TR, under 18 and $24 \mathrm{~h}$ incubation periods ( $18 \mathrm{~h}: \mathrm{F}_{3,119}=9.4$, $p<0.001 ; 24$ h: $\left.\mathrm{F}_{3,119}=9.7, p<0.001\right)$. Metarhizium anisopliae spores ceased to grow after 8 days of exposure to Lurem-TR; whereas, they continued growth beyond the same duration of time when exposed to $M$. sjostedti and F. occidentalis aggregation pheromones. During $18 \mathrm{~h}$ of incubation, there was a significant difference in fungal spore growth between the control, the major compounds of $M$. sjostedti, and F. occidentalis aggregation pheromones and Lurem-TR. No significant difference was found in the germ tube growth of $M$. anisopliae exposed to $M$. sjostedti and F. occidentalis aggregation pheromones at $18 \mathrm{~h}$ incubation period (Figure 2A). However, at 24-h incubation time, significant differences were found in the germ tube growth of M. anisopliae isolate ICIPE 69 exposed to all thrips attractants (Figure 2B). The germ tube growth of M. anisopliae isolate ICIPE 69 was significantly reduced as compared to the control after exposure to the major aggregation pheromone compounds of M. sjostedti (22.5-26.1\%) and F. occidentalis (13.5-10.4\%) and Lurem-TR (63.7-58.4\%) at $24 \mathrm{~h}$ of incubation (Figure $2 \mathrm{~B})$.
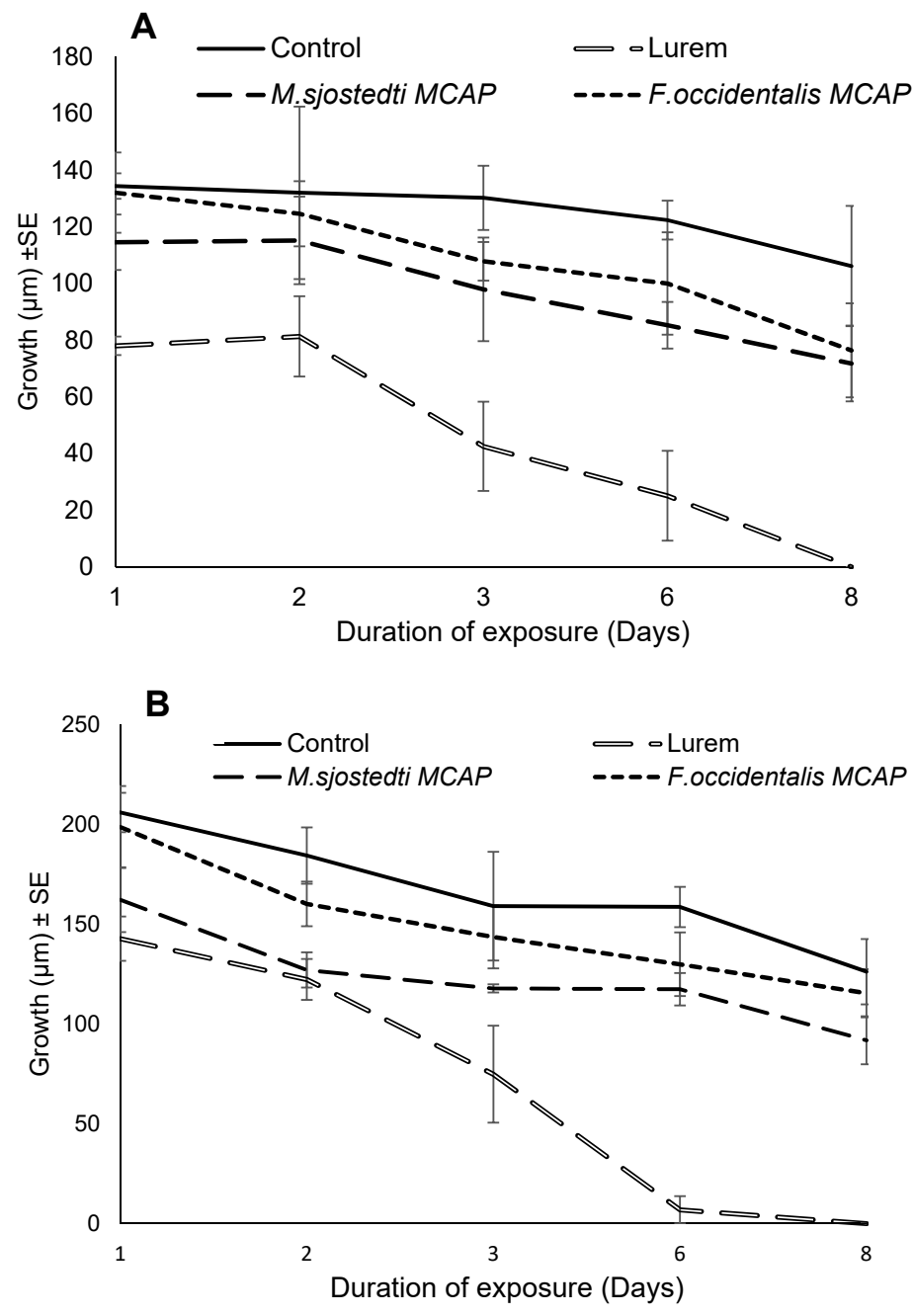

Figure 2. Effect of thrips aggregation pheromones and non-pheromone attractant on M. anisopliae germ tube growth ( $\mu \mathrm{m} /$ day) after 0 to 8 days of exposure at $18 \mathrm{~h}(\mathbf{A})$ and $24 \mathrm{~h}(\mathbf{B})$ incubation times at $30 \mu \mathrm{g}$ dose per attractant. MCAP: major component of aggregation pheromones. 
There was no significant interaction effect between the test thrips attractants and number of exposure days at $18 \mathrm{~h}$ incubation period $\left(\mathrm{F}_{12,119}=1.4 ; p=0.2\right)$; whereas, a significant interaction was found at $24 \mathrm{~h}$ incubation period $\left(\mathrm{F}_{12,119}=2.5 ; p<0.001\right)$.

\subsection{Attraction of M. sjostedti to the Major Compound of Its Aggregation Pheromone}

During the field experiment conducted in September 2018, there was a significant effect of the major compound doses on female $M$. sjostedti catches $\left(\mathrm{F}_{3,63}=2.7 ; p<0.001\right)$, but there was no clear attraction. No significant differences were found for male catches $\left(\mathrm{F}_{3,63}=3.32\right.$; $p=0.06$ ) (Figure 3A). For females, the $30 \mu \mathrm{g}$ dose was not significantly different in trap catch compared to the control while $300 \mu \mathrm{g}$ repelled (Figure 3A). Significant differences were obtained with adult $M$. sjostedt $i$ female catches from experiments conducted in January 2019 $\left(\mathrm{F}_{3,63}=32.7 ; p<0.001\right)$ and February $2019\left(\mathrm{~F}_{3,63}=24 ; p<0.001\right)$, respectively. The treatment with $30 \mu \mathrm{g}$ dose of $(R)$-lavandulyl 3-methylbutanoate increased trap catches 4 and 2.5 times more than the control in January and February respectively (Figure 3B,C). Similarly, there were significant differences between major compound doses on male M. sjostedti trap catches during the field experiments conducted in January $\left(\mathrm{F}_{3,63}=21.7 ; p<0.001\right)$ and February $2019\left(\mathrm{~F}_{3,63}=14.5 ; p<0.001\right)$ (Figure 3B,C). The percentage increases and decreases in trap catches of males were small and not consistent.

$\mathbf{A}$

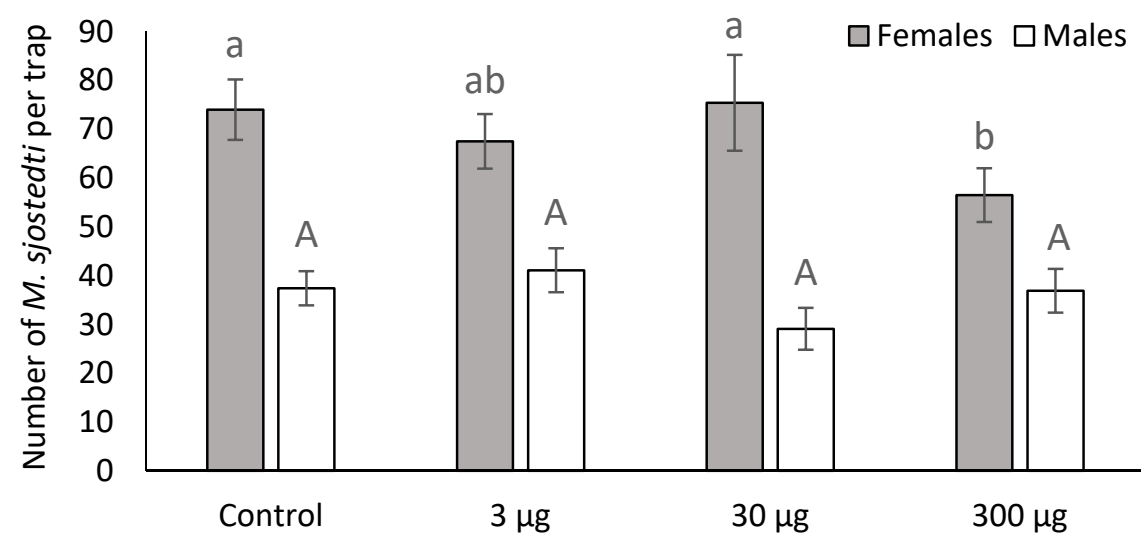

B

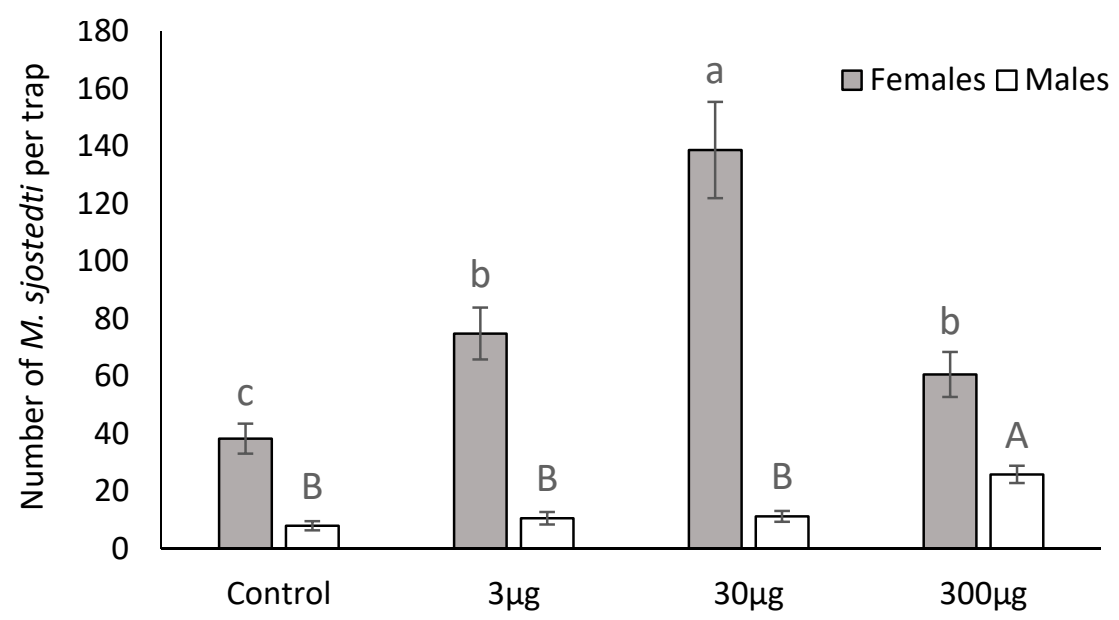

Figure 3. Cont. 


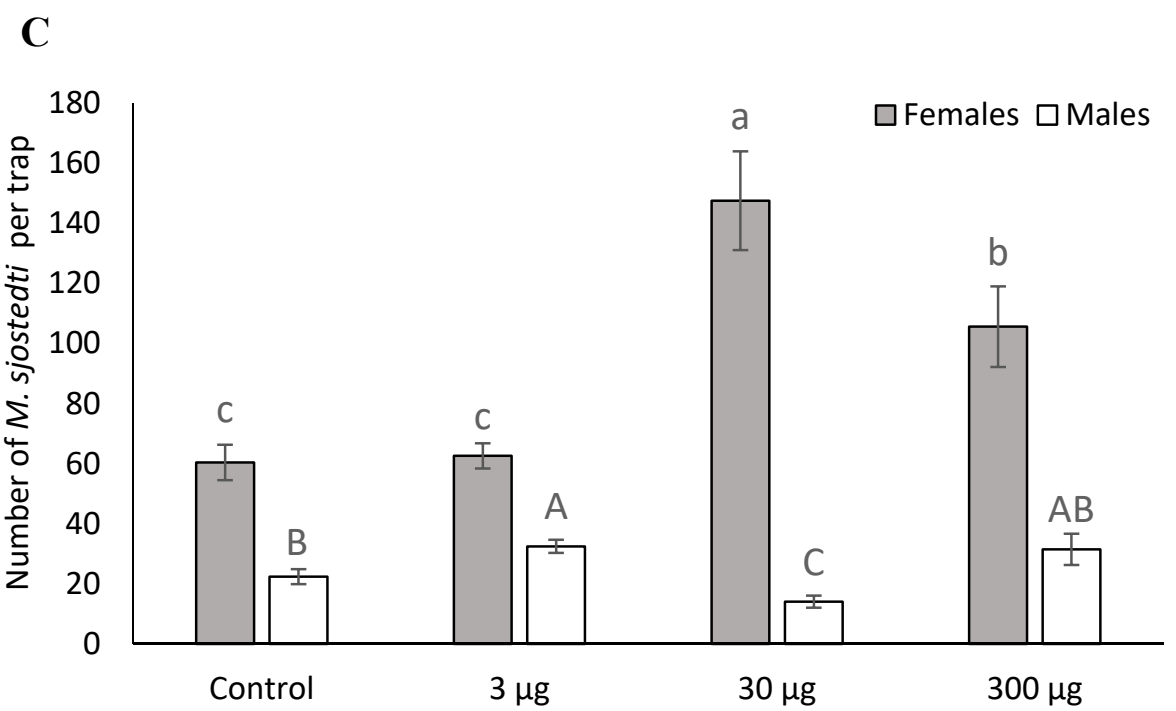

Figure 3. Effect of different doses of major compound on trap catch of female and male M. sjostedti during field experiments in September 2018 (A), January 2019 (B), and February 2019 (C) at Mbita, western Kenya. Means bearing the same uppercase or lowercase letters are not significantly different by Tukey HSD test at $95 \%$ confidence.

\subsection{Effect of M. sjostedti Aggregation Pheromone on M. anisopliae Viability in an} Autoinoculation Device

The placement of major compound of $M$. sjostedti aggregation pheromone inside or above the autoinoculation device did not affect $M$. anisopliae viability after 12 days of exposure in the field $\left(\mathrm{F}_{2,72}=1.33 ; p=0.26\right)$. The overall $M$. anisopliae viability recorded in the control device $(88.2 \pm 1.3 \%)$ was similar to the set-up with direct exposure (without spatial separation) to $(R)$-lavandulyl 3-methylbutanoate $(87.4 \pm 1.2 \%)$ and the set-up where the pheromone compound was spatially separated from the spores $(86.8 \pm 1.4 \%)$.

However, significant differences occurred during days of exposure $\left(\mathrm{F}_{2,72}=1.33\right.$; $p<0.001)$ and for the interaction between pheromone placement and day of exposure $\left(\mathrm{F}_{2,72}=4.71 ; p<0.001\right)$ (Figure 4$)$.

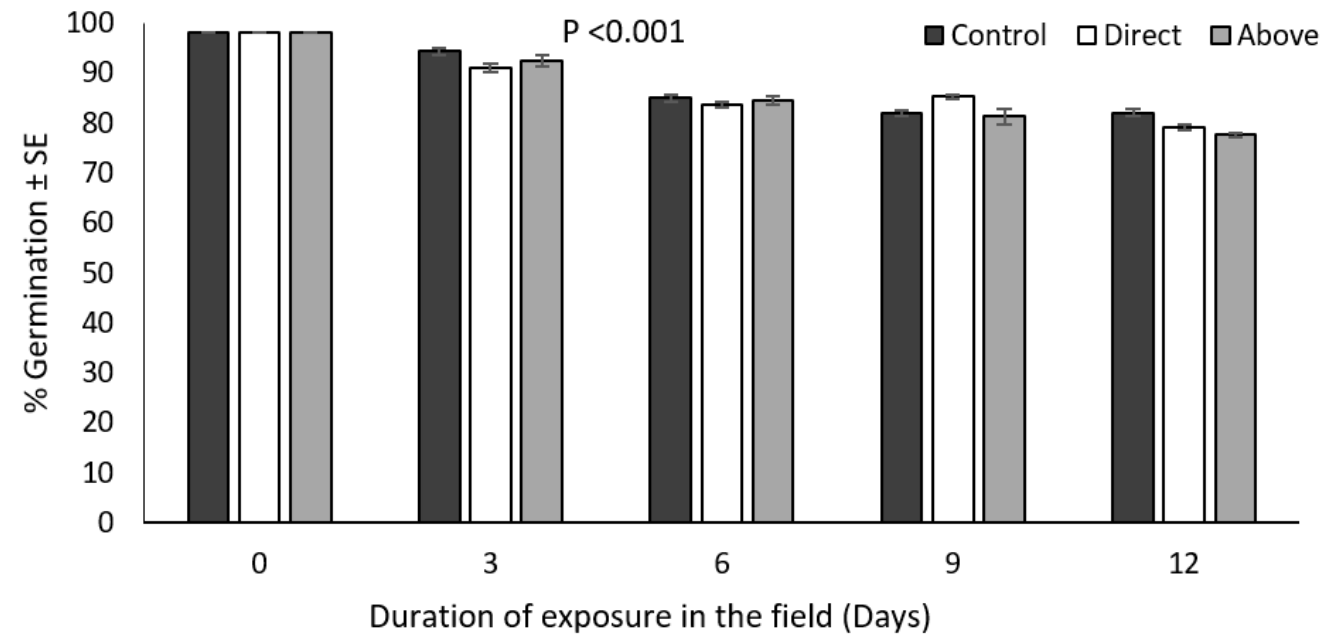

Figure 4. Effect of exposure. Duration and placement position of (R)-lavandulyl 3-methylbutanoate (used with autoinoculation device) on M. anisopliae viability under realistic field condition.

\section{Discussion}

The lure-and-kill or lure-and-infect concept using entomopathogens and semiochemicals has been demonstrated on several insect pests $[12,18,34]$. The efficacy of this approach relies on the compatibility between the attractant and the killing agent/biopesticides, which 
in turn necessitates optimization of spatial or temporal separation between the attractant and the killing agent $[18,19]$.

In this study, the newly identified bean flower thrips aggregation pheromones, i.e., $(R)$ lavandulyl 3-methylbutanoate (major component) and (R)-lavandulol (minor component) were found to have a dose-dependent antifungal effect as seen by conidial viability and germ tube growth of $M$. anisopliae. Our study also showed that exposure of $M$. anisopliae to $M$. sjostedti and F. occidentalis aggregation pheromones and Lurem-TR caused a decline in conidial viability and germ tube growth, where lowest spore viability and growth were recorded due to exposure to Lurem-TR. These results concur with Cole [35], who showed that semiochemicals utilized by insects for communication were variably toxic to various fungi. The deleterious effects of Lurem-TR on fungal viability and germ tube growth have already been demonstrated in previous studies $[18,20]$. However, our current study is the first to report on the antifungal properties of thrips aggregation pheromones. The compatibility between semiochemicals with entomopathogenic fungi (EPF) has been assessed in several other studies [36]. For example, Opisa et al. [37] reported incompatibility between phenylacetaldehyde (PAA) and M. anisopliae isolate ICIPE 30 to control Spoladea recurvalis (Lepidoptera: Crambidae). In addition, Nana et al. [38] reported incompatibility between attraction-aggregation-attachment pheromone (AAAP) with EPF isolate ICIPE 7 used to manage Rhipicephalus sp. (Ixodida: Ixodidae).

The chemical nature of an insect semiochemical is also likely to impact its compatibility with biopesticides $[18,20,36]$. The active ingredient of Lurem-TR, methyl-isonicotinate, is an ester of a 4-pyridyl-carboxylic acid [39], while the M. sjostedti and F. occidentalis aggregation pheromones are terpenoids [14,23,40-42]. Similarity in the chemistry of M. sjostedti and F. occidentalis pheromones may account for their similar antifungal effects on $M$. anisopliae and their difference from Lurem-TR. The antifungal properties of terpenoid compounds, including other semiochemicals, have been extensively reported [43-45]. Haque et al. [43] showed that terpenoids play a role in diminishing mitochondrial content, which results in an altered level of reactive oxygen species (ROS) and ATP generation leading to death of yeast cells of Saccharomyces cerevisiae.

In our study, we observed that at longer incubation time, the major component of $M$. sjostedti aggregation pheromone showed more antifungal effects on $M$. anisopliae germ tube length than the F. occidentalis compound. The difference between the two terpenoids could be due to the difference in their chemical structures [46].

In field experiments, the M. sjostedti aggregation pheromone had significant effects on $M$. sjostedti catches. The dose of $30 \mu \mathrm{g}$ was the most effective in increasing female M. sjostedti trap catch. This is the first report of the major component of the M. sjostedti aggregation pheromone increasing trap catches in the field. However, the M. sjostedti catches obtained with $30-\mu \mathrm{g}$ dose were variable through the seasons. For example, during the rainy season, the catches of females with the $30-\mu \mathrm{g}$ dose were not significantly different from the control and no effect was found on male M. sjostedti catches (Figure 3A), while significant and consistent effects with the same dose were found in January and February during the dry season (Figure 3B,C). A 30- $\mu$ g dose of aggregation pheromone has also given significant increases in trap catch for other thrips species [40,41].

Despite the antifungal effects of thrips aggregation pheromones described above, the field-effective dose of $30 \mu \mathrm{g}$ for the major compound of $M$. sjostedti aggregation pheromone is compatible with EPF (see Figures 1 and 2). This critical result suggests that $M$. sjostedti pheromone can be integrated with an autoinoculation device or spot spray application and does not necessarily need to be separated from the fungus, which makes the design and use simpler.

In the semi-field experiment to test the compatibility of the effective dose of the major compound with the entomopathogenic fungi in autoinoculation devices, conidia viability of $M$. anisopliae decreased slightly over time in all treatments. However, in all autoinoculation devices used, at least $86 \%$ of $M$. anisopliae conidia remained viable for 12 days post-exposure. Mfuti et al. [24] reported $>45 \%$ conidial viability for 12-15 days 
post-exposure in an autoinoculation device where the spores were directly exposed to methyl anthranilate or spatially separated, in the case of Lurem-TR. In all cases, either conidial spores of the fungus were well protected from the environmental stressors or the attractants were either compatible with the fungus or they were spatially separated. In contrast, Niassy et al. [18] reported a decrease in conidia viability from $80 \%$ to $6 \%$ at 2 - and 7-day post-inoculation in an autoinoculation device baited with Lurem-TR.

In summary, our study demonstrates that the M. sjostedti and F. occidentalis aggregation pheromones possess dose-dependent antifungal properties on $M$. anisopliae conidia. However, at $30 \mu \mathrm{g}$ dose, which is a suitable dose for field applications, the major $M$. sjostedti aggregation pheromone does not affect conidial viability or germ tube growth and hence does not require spatial separation in an autoinoculation device. This is the first demonstration that the major component of $M$. sjostedti aggregation pheromone can increase trap catches in the field and has a potential for use in a lure-and-kill strategy to control thrips. Furthermore, during the semi-field experiment, the compatibility of the $30 \mu \mathrm{g}$ dose with the fungus was confirmed irrespective of the placement set-ups of the pheromone in the autoinoculation device. We recommend future studies on the field efficacy for the control of $M$. sjostedti using autoinoculation devices or spot spray application.

Author Contributions: D.K.M., W.D.J.K., S.N., A.T., A.O.A. and S.S. conceived and designed the experiments. D.K.M. carried out the experiments. D.K.M., S.N., H.C., A.T., and S.S. analyzed and interpreted the data. W.D.J.K., S.S., A.T., M.O., F.P.D., T.W.P., and S.S. contributed reagents, and materials. S.S., W.D.J.K., T.W.P., A.T., S.N., and D.K.M. contributed to the writing of the manuscript. W.D.J.K., A.T., T.W.P., M.O., F.P.D., and S.S. obtained funding. All authors have read and agreed to the published version of the manuscript.

Funding: This research was funded by the BBSRC Global Challenges Research Fund (GCRF) Foundation Award (SAFARI) BB/P022391/1. icipe gratefully acknowledge the financial support by UK's Foreign, Commonwealth \& Development Office (FCDO), Swedish International Development Cooperation Agency (Sida), the Swiss Agency for Development and Cooperation (SDC), the Federal Democratic Republic of Ethiopia and the Kenyan Government. The views expressed herein do not necessarily reflect the official opinion of the donors.

Institutional Review Board Statement: Not applicable.

Informed Consent Statement: Not applicable.

Data Availability Statement: Data is contained within the article and also available upon request from the authors.

Acknowledgments: We thank Jane Kimemia, Nelson Mwando, and Basilio Njiru for assisting in preparing fungal suspension, making pheromone dilutions, measuring fungal growth, and cleaning septa. We are grateful to Daisy Salifu of icipe for the statistical guidance. We are grateful to Elisabeth Aoko, Pascal Oreng, Victor Otieno, Samuel Otieno for field assistance.

Conflicts of Interest: The authors declare no conflict of interest.

\section{References}

1. Abate, T.; Alene, A.D.; Bergvinson, D.; Shiferaw, B.; Silim, S.; Orr, A.; Asfaw, S. Tropical Grain Legumes in Africa and South Asia. Knowledge and Opportunities; ICRISAT-CIAT-IITA, Ed.; IITA: Nairobi, Kenya, 2012.

2. Maphosa, Y.; Jideani, V.A. The Role of Legumes in Human Nutrition. 2017. Available online: http://dx.doi.org/10.5772/ intechopen.69127 (accessed on 2 June 2021).

3. Mfuti, D.K.; Niassy, S.; Subramanian, S.; du Plessis, H.; Ekesi, S.; Maniania, N.K. Lure and infect strategy for application of entomopathogenic fungus for the control of bean flower thrips in cowpea. Biol. Control 2017, 107, 70-76. [CrossRef]

4. Sobda, G.; Boukar, O.; Tongoona, P.B.; Ayertey, J.; Offei, K.S. Quantitative trait loci (QTL) for cowpea resistance to flower bud thrips (Megalurothrips sjostedti Trybom). Int. J. Plant Breed. Genet. 2017, 4, 292-299.

5. Tamò, M.; Baumgärtner, J.; Delucchi, V.; Herren, H.R. Assessment of key factors responsible for the pest status of the bean flower thrips Megalurothrips sjostedti (Trybom) (Thysanoptera, Thripidae) in West Africa. Bull. Entomol. Res. 1993, 83, 251-258. [CrossRef]

6. Ngakou, A.; Tamò, M.; Parh, I.A.; Nwaga, D.; Ntonifor, N.N.; Korie, S.; Nebane, C.L.N. Management of cowpea flower thrips, Megalurothrips sjostedti (Thysanoptera, Thripidae), in Cameroon. Crop Prot. 2008, 27, 481-488. [CrossRef] 
7. Niassy, S.; Ekesi, S.; Maniania, N.K.; Orindi, B.; Moritz, G.B.; de Kogel, W.J.; Subramanian, S. Active aggregation among sexes in bean flower thrips (Megalurothrips sjostedti) on cowpea (Vigna unguiculata). Entomol. Exp. Appl. 2016, 158, 17-24. [CrossRef] [PubMed]

8. Tamò, M.; Arodokoun, D.Y.; Zenz, N.; Tindo, M.; Agboton, C.; Adeoti, R. The Importance of Alternative Host plants for the Biological Control of Two Key Cowpea Insect Pests, the Pod Borer Maruca vitrata (Fabricius) and the Flower Thrips, Megalurothrips sjostedti (Trybom). In Proceedings of the 3rd World Cowpea Conference, Ibadan, Nigeria, 5-10 September 2000; pp. 81-93.

9. Abtew, A.; Niassy, S.; Affognon, H.; Subramanian, S.; Kreiter, S.; Garzia, G.T.; Martin, T. Farmers' knowledge and perception of grain legume pests and their management in the eastern province of Kenya. Crop Prot. 2016, 87, 90-97. [CrossRef]

10. Jackai, L.E.N.; Adalla, C.B. Pest Management Practices in Cowpea: A Review. In Advances in Cowpea Research; Singh, B.B., Mohan Raj, D.R., Dashiella, K.E., Jackai, L.E.N., Eds.; Co-Publication of International Institute of Tropical Agriculture (IITA) and Japan International Research Centre for Agricultural Sciences (JIRCAS): Ibadan, Nigeria, 1997; pp. 240-258.

11. Ekesi, S.; Chabi-Olaye, A.; Subramanian, S.; Borgemeister, C. Horticultural pest management and the African economy: Successes, challenges and opportunities in a changing global environment. In Proceedings of the All Africa Horticultural Congress, Nairobi, Kenya, 31 August 2009; pp. 165-183.

12. Maniania, N.K. A low-cost contamination device for infecting adult tsetse flies, Glossina spp., with the entomopathogenic fungus Metarhizium anisopliae in the field. Biocontrol Sci. Technol. 2002, 12, 59-66. [CrossRef]

13. Niassy, S.; Maniania, N.K.; Subramanian, S.; Gitonga, L.M.; Mburu, D.M.; Masiga, D.; Ekesi, S. Selection of promising fungal biological control agent of the western flower thrips Frankliniella occidentalis (Pergande). Lett. Appl. Microbiol. 2012, 54, 487-493. [CrossRef]

14. Niassy, S.; Tamiru, A.; Hamilton, J.G.C.; Kirk, W.D.J.; Mumm, R.; Sims, C.; de Kogel, W.J.; Ekesi, S.; Maniania, N.K.; Bandi, K.; et al. Characterization of male-produced aggregation pheromone of the bean flower thrips Megalurothrips sjostedti (Thysanoptera: Thripidae). J. Chem. Ecol. 2019. [CrossRef]

15. Dimbi, S.; Maniania, N.K.; Ekesi, S. Horizontal transmission of Metarhizium anisopliae in fruit flies and effect of fungal infection on egg laying and fertility. J. Insects 2013, 4, 206-216. [CrossRef]

16. Hedström, I.; Monge-Nájera, J. Is sexually transmitted fungal infection evidence for size-related mating success in neotropical guava fruit flies? J. Trop. Biol. 1998, 46, 1129-1132.

17. Dimbi, S.; Maniania, N.K.; Lux, S.A.; Ekesi, S.; Mueke, J.M. Pathogenicity of Metarhizium anisopliae (Metsch.) Sorokin and Beauveria bassiana (Balsamo) Vuillemin to three adult fruit ßy species: Ceratitis capitata (Weidemann), C. rosa var. fasciventris Karsch and C.cosyra (Walker) (Diptera: Tephritidae). Mycopathologia 2003, 156, 375-382. [CrossRef]

18. Niassy, S.; Maniania, N.K.; Subramanian, S.; Gitonga, L.M.; Ekesi, S. Performance of a semiochemical-baited autoinoculation device treated with Metarhizium anisopliae for control of Frankliniella occidentalis on French bean in field cages. Entomol. Exp. Appl. 2012, 142, 97-103. [CrossRef]

19. Mfuti, D.K.; Subramanian, S.; van Tol, R.W.H.M.; Wiegers, G.L.; De Kogel, W.J.; Niassy, S.; Du Plessis, H.; Ekesi, S.; Maniania, N.K. Spatial separation of semiochemical Lurem-TR and entomopathogenic fungi to enhance their compatibility and infectivity in an autoinoculation system for thrips management. Pest Manag. Sci. 2016, 72, 131-139. [CrossRef]

20. Mfuti, D.K.; Subramanian, S.; Niassy, S.; Salifu, D.; du Plessis, H.; Ekesi, S.; Maniania, N.K. Screening for attractants compatible with entomopathogenic fungus Metarhizium anisopliae for use in thrips management. Afr. J. Biotechnol. 2016, 15, 714-721.

21. Pepper, H.P.; Tulip, S.J.; Nakano, Y.; George, J.H. Biomimetic total synthesis of ( \pm )-doitunggarcinone A and (+)-garcibracteatone. J. Org. Chem. 2014, 79, 2564-2573. [CrossRef] [PubMed]

22. Sampson, C.; Kirk, W.D.J. Can mass trapping reduce thrips damage and is it economically viable? Management of the western flower thrips in strawberry. PLoS ONE 2013, 8, e80787. [CrossRef] [PubMed]

23. Kirk, W.D.J. The aggregation pheromones of thrips (Thysanoptera) and their potential for pest management. Int. J. Trop. Insect Sci. 2017, 37, 41-49. [CrossRef]

24. Mfuti, D.K.; Subramanian, S.; Niassy, S.; du Plessis, H.; Ekesi, S.; Maniania, N.K. Semiochemical-baited autodissemination device for managing BFT on cowpea. In Sustainable Management of Invasive Pests in Africa; Niassy, S., Ekesi, S., Migiro, L., Otieno, W., Eds.; Springer: Cham, Switzerland, 2020; pp. 253-266.

25. Davidson, M.M.; Butler, R.C.; Winkler, S.; Teulon, D.A.J. Pyridine compounds increase trap capture of Frankliniella occidentalis (Pergande) in a covered crop. N. Z. Plant Prot. 2007, 60, 56-60. [CrossRef]

26. Muvea, A.M.; Waiganjo, M.M.; Kutima, H.L.; Osiemo, Z.; Nyasani, J.O.; Subramanian, S. Attraction of pest thrips (Thysanoptera: Thripidae) infesting French beans to coloured sticky traps with Lurem-TR and its utility for monitoring thrips populations. Int. J. Trop. Insect Sci. 2014, 34, 197-206.

27. Teulon, D.A.J.; Davidson, M.M.; Perry, N.B.; Nielsen, M.-C.; Castañé, C.; Bosch, D.; Riudavets, J.; van Tol, R.W.H.M.; de Kogel, W.J. Methyl isonicotinate-A non-pheromone thrips semiochemical and its potential for pest management. Int. J. Trop. Insect Sci. 2017, 37, 50-56. [CrossRef]

28. Luque de Castro, M.D.; Ayuso, G.L.E. Soxhlet Extraction, Environmental Applications. 2000. Available online: https://www. sciencedirect.com/science/article/pii/B0122267702066813 (accessed on 2 June 2021).

29. Cooke, V.M.; Miles, R.J.; Price, R.G.; Midgley, G.; Khamri, W.; Richardson, A.C. New chromogenic agar medium for the identification of Candida spp. Appl. Environ. Microbiol. 2002, 68, 3622-3627. [CrossRef] 
30. Maniania, N.K. A laboratory technique for infecting adult Tsetse with a fungal pathogen. Insect Sci. Its Appl. 1994, 15, 421-426. [CrossRef]

31. Inglis, G.D.; Enkerli, J.; Goettel, M.S. Laboratory techniques used for entomopathogenic fungi: Hypocreales. In Manual of Techniques in Invertebrate Pathology, 2nd ed.; Lacey, L.A., Ed.; Academic Press: San Diego, CA, USA, 2012; pp. $189-253$.

32. Searle, S.R.; Speed, F.M.; Milliken, G.A. Population marginal means in the linear model: An alternative to least squares means. Am. Stat. 1980, 34, 216-221.

33. R Development Core Team. A Language and Environment for Statistical Computing; R Foundation for Statistical Computing: Vienna, Austria, 2014.

34. Migiro, L.N.; Maniania, N.K.; Chabi-Olaye, A.; Vandenberg, J. Pathogenicity of entomopathogenic fungi Metarhizium anisopliae and Beauveria bassiana (Hypocreales: Clavicipitaceae) isolates to the adult pea leafminer (Diptera: Agromyzidae) and prospects of an autoinoculation device for infection in the field. Environ. Entomol. 2010, 39, 468-475. [CrossRef]

35. Cole, L.K.; Blum, M.S.; Roncadori, R.W. Antifungal properties of the insect alarm pheromones, citral, 2-heptanone, and 4-methyl3-heptanone. Mycologia 1975, 67, 701-708. [CrossRef]

36. Sharma, A.; Sandhi, R.K.; Reddy, G.V.P. A Review of interactions between insect biological control agents and semiochemicals. Insects 2019, 10, 439. [CrossRef] [PubMed]

37. Opisa, S.; Du Plessis, H.; Akutse, K.S.; Fiaboe, K.K.M.; Ekesi, S. Horizontal transmission of Metarhizium anisopliae between Spoladea recurvalis (Lepidoptera: Crambidae) adults and compatibility of the fungus with the attractant phenylacetaldehyde. Microb. Pathog. 2019, 131, 197-204. [CrossRef] [PubMed]

38. Nana, P.; Maniania, N.K.; Maranga, R.O.; Boga, H.I.; Kutima, H.L.; Eloff, J.N. Compatibility between Calpurnia aurea leaf extract, attraction aggregation and attachment pheromone and entomopathogenic fungus Metarhizium anisopliae on viability, growth and virulence of the pathogen. J. Pest Sci. 2012, 85, 109-115. [CrossRef]

39. Davidson, M.M.; Perry, N.B.; Larsen, L.; Green, V.C.; Butler, R.C.; Teulon, D.A.J. 4-Pyridyl carbonyl compounds as thrips lures: Effectiveness for western flower thrips in Y-tube bioassays. J. Agric. Food Chem. 2008, 56, 6554-6561. [CrossRef]

40. Akella, S.V.S.; Kirk, W.D.J.; Lu, Y.-B.; Murai, T.; Walters, K.F.A.; Hamilton, J.G.C. Identification of the aggregation pheromone of the melon thrips, Thrips palmi. PLoS ONE 2014, 9, e103315. [CrossRef] [PubMed]

41. Hamilton, J.G.C.; Hall, D.R.; Kirk, W.D.J. Identification of a male-produced aggregation pheromone in the western flower thrips Frankliniella occidentalis. J. Chem. Ecol. 2005, 31, 1369-1379. [CrossRef]

42. Liu, P.; Qin, Z.; Feng, M.; Huang, X.; Shi, W. The male-produced aggregation pheromone of the bean flower thrips Megalurothrips usitatus in China: Identification and attraction of conspecifics in the laboratory and field. Pest Manag. Sci. 2020. [CrossRef] [PubMed]

43. Haque, E.; Irfan, S.; Kamil, M.; Sheikh, S.; Hasan, A.; Ahmad, A.; Lakshmi, V.; Nasir, A.; Mir, S.S. Terpenoids with antifungal activity trigger mitochondrial dysfunction in Saccharomyces cerevisiae. Microbiology 2016, 85, 436-443. [CrossRef]

44. Kamatou, G.P.P.; Vermaak, I.; Viljoen, A.M.; Lawrence, B.M. Menthol: A simple monoterpene with remarkable biological properties. Phytochemistry 2013, 96, 15-25. [CrossRef] [PubMed]

45. Miron, D.; Battistia, F.; Silvab, F.K.; Lanab, A.D.; Pippib, B.; Casanovac, B.; Gnoattoc, S.; Fuentefriab, A.; Mayorgad, P.; Schapovala, E.E.S. Antifungal activity and mechanism of action of monoterpenes against dermatophytes and yeasts. Rev. Bras. Farmacogn. 2014, 24, 660-667. [CrossRef]

46. Rao, A.; Zhang, Y.; Muend, S.; Rao, R. Mechanism of antifungal activity of terpenoid phenols resembles calcium stress and inhibition of the tor pathway. Antimicrob. Agents Chemother. 2010, 54, 5062-5069. [CrossRef] 